\title{
Duration or Timing? What is the Optimal Core for Older Adults to Engage in Moderate-to-vigorous Physical Activity to Prevent Disability?
}

\author{
Ting-Fu Lai \\ National Taiwan Normal University \\ Yung Liao \\ National Taiwan Normal University \\ Chien-Yu Lin \\ Waseda University \\ Wan-Chi Huang \\ National Taiwan Normal University \\ Ming-Chun Hsueh \\ University of Taipei \\ Ding-Cheng Chan ( $\nabla$ dingchengchan@ntu.edu.tw) \\ National Taiwan University Hospital Chutung Branch
}

\section{Short paper}

Keywords: aging, timing of physical ability, circadian clock

Posted Date: July 16th, 2020

DOI: https://doi.org/10.21203/rs.3.rs-41437/v1

License: () (1) This work is licensed under a Creative Commons Attribution 4.0 International License. Read Full License 


\section{Abstract}

Background The positive association between the total duration of physical activity and performances of physical function may vary at different times of the day as circadian rhythm regulates individuals in response to external stimulations. We aimed to examine the association of timing-specific and overall moderate-to-vigorous physical activity (MVPA) with performances of physical function in older adults.

Methods A cross-sectional analysis was conducted among 118 older adults (mean age $=70.0 \pm 5.0$ years). We assessed and identified timing-specific (morning: 06:01-12:00; afternoon: 12:01-18:00; evening: 18:01-24:00) and overall MVPA using a triaxial accelerometer. Different measures of physical function were evaluated including handgrip strength (by grip dynamometer), gait speed (five-meter walk test), basic functional mobility (timed up and go test), and lower limb strength (five times sit-to-stand test). Multivariate linear regression models adjusting for covariates were used to investigate the associations. Results Participants spent 0.4 hours in MVPA per day on average, half the time spent during the morning (47.7\%), followed by during the afternoon (29.9\%) and evening (21.6\%). The time spent on overall MVPA was generally associated with better physical function performances. There was statistical evidence for the percentages of MVPA engagement during the morning $(B=0.214,95 \%$ confidence interval $[\mathrm{Cl}] 0.001$ to 0.428$)$ and afternoon $(\mathrm{B}=-0.273,95 \% \mathrm{Cl}-0.518$ to -0.027) associated with basic functional mobility but with contrary directions; the percentage of MVPA engagement during the evening was associated with less time spent in gait speed performance ( $B=-0.237,95 \% \mathrm{Cl}-0.468$ to -0.006 ).

Conclusions Our findings inform implications that the overall MVPA engagement was more important than timing-specific MVPA to older adults' physical function performances. Strategies for accumulating time of MVPA is more practical and effective than encouraging to engage MVPA in specific timing for the enhancement of functional ability and therefore prevent disability among older adults.

\section{Background}

Disability, a physical or mental condition that impairs or limits an individual's movements in daily life, is one of the commonest symptoms in older populations; the prevalence was estimated to be $25 \%$ in the population aged over 65 years in 2008 in the United States [1]. It places not only a heavy burden of physical strain and emotional stress on the family caregiver [2] but also an increase in medical care expenditure [3]. Several studies have shown that physical function is an important predictor of disability in older adults $[4,5]$. Previous research addressing older adults' disability has shown that engaging sufficient levels of moderate-to-vigorous physical activity (MVPA) contributes to better performances of physical function (e.g., handgrip strength, gait speed, basic functional mobility, and lower limb strength) [6-8].

There is a growing interest in establishing a link between the effects of circadian rhythms and sufficient physical activity in older adults [9]. An individual's circadian rhythm is dynamic over their lifespan and deteriorates in the later years of life [9]; however, it still regulates individuals' physiology and metabolism in response to external stimulations $[10,11]$. Previous studies have indicated that older adults who were more active, indicated by the amount of physical activity or walking time, during the morning had lower risks of obesity [12] and mortality [13]. Despite this, the relationship between timing-specific physical activity and physical function remains to be investigated. There may be an optimal time of the day for MVPA engagement to modify human circadian rhythms and maximize physical function in the aged populations.

There are several measurements to assess physical activity at different times of the day and the accelerometer is one of the ideal measurements. The accelerometer tracks the orientation and movement in individuals objectively [14], records the changes in small time increments, and therefore accurately identifies different timings of the day for older adults' MVPA. Measurement by accelerometer can address the limitations of reporting and recall biases [15].

We hypothesized that the MVPA engagement during the morning was associated with older adults' physical function after controlling for its overall duration and therefore investigated the association of timing-specific and overall MVPA with a range of measures of physical function among community-dwelling older adults.

\section{Methods}

\subsection{Participants}

Older adults aged over 60 years who could walk independently were recruited using local advertisements and announcements from 28 different residential neighborhoods in Taipei City, Taiwan. Among these participants, 118 out of 130 older adults wearing the 
accelerometer for a consecutive seven days completed the on-site examinations. There were no differences in sex and age in the included and excluded participants (data not shown). Detailed methods and procedures have been reported elsewhere [16].

\subsection{Outcome variables}

Several measures of physical function, which have been validated for the evaluation of physical function in older adutls [17], were assessed by on-site examinations:

1. Handgrip strength: We measured the handgrip strength of both of the participant's hands using the hydraulic hand dynamometer (Jamar Plus + Digital Hand Dynamometer, Lafayette Instrument Company, USA). A higher measure of handgrip strength indicated better performance, and the maximum strength measurement was selected from three attempts with a one-minute gap between attempts.

2. Gait speed: Each participant had only one attempt to walk 11 meters as fast as possible. The time spent walking in the central five meters was calculated. A shorter time spent on the 5-meter walk test indicated better performance of gait speed.

3. Basic functional mobility: Participants were instructed to rise from a standard chair, walk three meters forward, return to the chair, and sit down as soon as possible. Each participant repeated the same attempt twice and the attempt with the shorter time, indicating better performance, was used in the analyses.

4. Lower limb strength: We assessed lower limb strength using the five times sit-to-stand test. Participants were requested to sit on a standard chair and repeat stand up and sit down five times, as fast as they could. Each participant had two attempts and the attempt with the shorter time, indicating better performance, was selected.

\subsection{Exposure variables}

Time spent in MVPA was measured by a triaxial accelerometer (ActiGraph GT3X+, Pensacola, FL, USA). We followed the information on data collection and processing criteria suggested by a systematic review of standard protocols [18]. The different time intervals were identified in which the MVPA ( $\geq 2,020$ counts/minute) occurred [19]: a) morning: 06:01-12:00; b) afternoon: 12:01-18:00; and c) evening: 18:01-24:00 based on previous studies $[13,19,20]$. We calculated the percentage of the three time intervals of MVPA engagement for each participant. The ActiLife software version 6.0 was used to process the accelerometer data.

\subsection{Covariates}

The covariates including i) sex, ii) age, iii) body mass index (BMl; calculated by weight in kilograms divided by height in meters squared), iv) marital status, v) employment, vi) living status, vii) educational level, viii) self-rated health, ix) depression, $\mathrm{x}$ ) diabetes, xi) hypertension, xii) hyperlipidemia and xiii) monitor wear time were assessed by an interviewer-administered questionnaire (i-xii) and an accelerometer (xiii).

\subsection{Statistical analyses}

We analyzed data from 118 older adults who completed all the study variables. We selected the covariates for different measures of the physical function using univariate linear regression models (Appendix Table 1). Unstandardized coefficients $(B)$ were used to estimate the associations of the time spent in timing-specific and overall MVPA with measures of the physical function using multivariate linear regression models after adjusting for their covariates (i.e., the variables showing statistically significant in the univariate analyses). Logtransformed values of the study variables were used if the distributions of their raw values were skewed. All analyses were conducted in IBM SPSS Statistics 23.0 and the significance level was set at $p<0.05$.

\section{Results}

The characteristics of 118 older adults ( $70.3 \%$ female; mean age $=70.0$ years) were presented in Table 1 . Participants spent 0.4 hours in MVPA per day on average, almost half the time was during the morning (47.7\%), followed by the time spent during the afternoon (29.9\%) and evening (21.6\%) (Table 1).

Table 2 shows the associations of timing-specific and overall MVPA with four measures of physical function. In the adjusted models, overall MVPA duration was generally associated with better performances in the measures of handgrip strength $(B=0.045,95 \%$ confidence interval $[\mathrm{Cl}] 0.017$ to 0.072$)$, gait speed $(B=-0.061,95 \% \mathrm{Cl}-0.091$ to -0.031$)$, and basic functional mobility $(B=-0.045,95 \% \mathrm{Cl}$ -0.079 to -0.011$)$. The associations of the percentages of MVPA during the morning $(B=0.214,95 \% \mathrm{Cl} 0.001$ to 0.428$)$ and afternoon ( $B=$ $-0.273,95 \% \mathrm{Cl}-0.518$ to -0.027 ) were associated with basic functional mobility, respectively. However, their associations were in contrary

Page $3 / 9$ 
directions. Additionally, there was statistical evidence for the percentage of MVPA during the evening was associated with better performance of gait speed $(B=-0.237,95 \% \mathrm{Cl}-0.468$ to -0.006$)$.

\section{Discussion}

Our data showed that the engagement in longer MVPA was generally associated with better performances of physical function and some statistical evidence for associations between specific-timing MVPA and physical function in older adults. To our knowledge, this is the first study examining the association between the time spent in MVPA at different times of the day and physical function in the context of older adults. Furthermore, we used an accelerometer to objectively measure MVPA and provide such robust data. There were some limitations to this study. First, the association of the percentages or duration of timing-specific and overall MVPA with physical function should be interpreted with caution, as the size of our study was small. Second, although we regarded the same period of the day for each participant as sleep duration (i.e., 00:00-06:00) so those older adults would not engage in physical activity at that period, there may be some inconsistency of lifestyle between participants and this may cause bias. However, our data showed that the sleep periods in more than $90 \%$ of the participants highly overlapped. Third, as we did not use a standardized procedure to screen the cognitive ability of participants before the on-site examinations, the older adults' understanding and reactions to the examinations may be confounded by their levels of cognition. Finally, the association of the percentages and duration of timing-specific and overall MVPA with physical function cannot be extrapolated as a causal relationship because of the cross-sectional design.

Our data showed positive associations of the overall duration of MVPA with performances of physical function. This result was consistent with previous studies, suggesting the engagement of MVPA could retain muscle density and function in older adults [6, 7, 21]. By contrast, our results did not show the benefits of physical function from higher levels of MVPA during the moring, inconsistent with previous findings $[12,13]$. Interestingly, there were diverse associations of the MVPA engaging in the morning and afternoon with the performance of basic functional mobility. Some studies suggested that the increased levels of serum vitamin $D$, which could be synthesized by sun exposure [22], could directly strengthen older adults' bones and muscles [23] as well as indirectly improve their muscle strength [24] through promoting sleep quality of older population [24, 25]. However, our result regarding the MVPA engagement during the morning and the performance of basic functional mobility did not fully support the hypothesis. It implied that sun exposure may not be the only reason to impact the associations between MVPA engagement and performances of physical function. There may be some other factors, especially work in the morning, that may influence this association. For example, a pilot showed preliminary evidence that exercising in the fasted or fed state during the early morning would have different effects on facilitating adaptations in muscle [26] and this may influence the association between the MVPA during the morning and physical function observed. Future research should investigate the pathway toward better physical function among older adults with comprehensive factors. There was a significant association between the MVPA engagement during the evening and the performance of gait speed. The association between evening MVPA engagement and gait speed may be attributable to the lower crime-related safety. Older adults who perceive themselves living in safer neighborhoods indicating by lower levels of crime and more comprehensive crossings were more likely to be associated with more MVPA [27] and lead to better physical function [28].

Despite some associations showed between the timing-specific MVPA and physical function, it seemed that the duration of MVPA engagement across the time of the day was more important to older adults' performances of physical function. Our findings may imply that older adults accumulated more duration of MVPA, even through interrupted sections, would have better performances of physical function, irrespective of the timing of the day for MVPA engagement.

\section{Conclusion}

This study suggests that engaging in more MVPA, regardless of the specific time of the day, is associated with better physical function performances among older adults. Designing strategies/programs with increasing the duration of MVPA engagement across the time of the day could benefit older adults' physically functional ability and may, therefore, prevent disability.

\section{Declarations}

\section{Ethics approval and consent to participate}

This study was approved by the Research Ethics Committee of National Taiwan Normal University (REC number: 201706HM020).

\section{Consent for publication}

Page $4 / 9$ 
Not Applicable.

\section{Availability of data and material}

Data used in this study are available upon reasonable requests.

\section{Competing interests}

The authors declare that there are no competing interests.

\section{Funding}

This study used personal grant received from the Ministry of Science and Technology of Taiwan (MOST 107-2410-H-003-117-MY2 and MOST 108-2622-8-003-001-TM1). The Ministry of Science and Technology of Taiwan was not involved in the study design, data collection process, analysis, interpretation, or writing of this manuscript.

\section{Authors' contributions}

D.-C.C., Y.L. and M.-C.H. conceptualised and designed the study. D.-C.C., Y.L. and M.-C.H. obtained funding for the research. T.-F.L. analysed and interpreted the data. M.-C.H. and W.-C.H. contributed to coordination and data collection. T.-F.L. and C.-C.L were major contributor in writing the manuscript. All authors read and improved the manuscript and approved the final manuscript.

\section{Acknowledgments}

This study was funded by personal grants received from the Ministry of Science and Technology, Taiwan (MOST 107-2410-H-003-117MY2 and MOST 108-2622-8-003-001-TM1). The Ministry of Science and Technology, Taiwan was not involved in the study design, data collection process, analysis, interpretation, or writing of this manuscript.

\section{References}

1. Hung WW, Ross JS, Boockvar KS, Siu AL. Recent trends in chronic disease, impairment and disability among older adults in the United States. BMC Geriatr. 2011;11:47-.

2. Papastavrou E, Kalokerinou A, Papacostas SS, Tsangari H, Sourtzi P. Caring for a relative with dementia: family caregiver burden. J Adv Nurs. 2007;58(5):446-57.

3. Connell CM, Janevic MR, Gallant MP. The costs of caring: impact of dementia on family caregivers. J Geriatr Psychiatry Neurol. 2001;14(4):179-87.

4. Donoghue OA, Savva GM, Cronin H, Kenny RA, Horgan NF. Using timed up and go and usual gait speed to predict incident disability in daily activities among community-dwelling adults aged 65 and older. Arch Phys Med Rehabil. 2014;95(10):1954-61.

5. Al Snih S, Graham JE, Ray LA, Samper-Ternent R, Markides KS, Ottenbacher KJ. Frailty and incidence of activities of daily living disability among older Mexican Americans. J Rehabil Med. 2009;41(11):892-7.

6. Santos DA, Silva AM, Baptista F, Santos R, Vale S, Mota J, et al. Sedentary behavior and physical activity are independently related to functional fitness in older adults. Exp Gerontol. 2012;47(12):908-12.

7. Keevil VL, Cooper AJM, Wijndaele K, Luben R, Wareham NJ, Brage S, et al. Objective Sedentary Time, Moderate-to-Vigorous Physical Activity, and Physical Capability in a British Cohort. Med Sci Sports Exerc. 2016;48(3):421-9.

8. Herman S, Kiely DK, Leveille S, O'Neill E, Cyberey S, Bean JF. Upper and Lower Limb Muscle Power Relationships in Mobility-Limited Older Adults. The Journals of Gerontology: Series A. 2005;60(4):476-80.

9. Weinert D, Waterhouse J. The circadian rhythm of core temperature: effects of physical activity and aging. Physiol Behav. 2007;90(23):246-56.

10. Hood S, Amir S. The aging clock: circadian rhythms and later life. J Clin Invest. 2017;127(2):437-46.

11. Sohail S, Yu L, Bennett DA, Buchman AS, Lim ASP. Irregular 24-hour activity rhythms and the metabolic syndrome in older adults. Chronobiol Int. 2015;32(6):802-13. 
12. Chomistek AK, Shiroma EJ, Lee IM. The Relationship Between Time of Day of Physical Activity and Obesity in Older Women. J Phys Act Health. 2016;13(4):416-8.

13. Klenk J, Dallmeier D, Denkinger MD, Rapp K, Koenig W, Rothenbacher D, et al. Objectively Measured Walking Duration and Sedentary Behaviour and Four-Year Mortality in Older People. PLoS One. 2016;11(4):e0153779-e.

14. Matthews CE. Physical activity in the United States measured by accelerometer: comment. Med Sci Sports Exerc. 2008;40(6):1188-9.

15. Phillips LJ, Petroski GF, Markis NE. A Comparison of Accelerometer Accuracy in Older Adults. Res Gerontol Nurs. 2015;8(5):213-9.

16. Chen B-I, Hsueh M-C, Rutherford R, Park J-H, Liao Y. The associations between neighborhood walkability attributes and objectively measured physical activity in older adults. PLoS One. 2019;14(9):e0222268-e.

17. Cooper R, Kuh D, Hardy RJB. Objectively measured physical capability levels and mortality: systematic review and meta-analysis. 2010;341:c4467.

18. Migueles JH, Cadenas-Sanchez C, Ekelund U, Delisle Nyström C, Mora-Gonzalez J, Löf M, et al. Accelerometer Data Collection and Processing Criteria to Assess Physical Activity and Other Outcomes: A Systematic Review and Practical Considerations. Sports Med. 2017;47(9):1821-45.

19. Troiano RP. Large-scale applications of accelerometers: new frontiers and new questions. Med Sci Sports Exerc. 2007;39(9):1501-.

20. Murray K, Godbole S, Natarajan L, Full K, Hipp JA, Glanz K, et al. The relations between sleep, time of physical activity, and time outdoors among adult women. PLoS One. 2017;12(9):e0182013.

21. Gebel K, Ding D, Bauman AE. Volume and intensity of physical activity in a large population-based cohort of middle-aged and older Australians: Prospective relationships with weight gain, and physical function. Prev Med. 2014;60:131-3.

22. Lips P. Vitamin D physiology. Progress in Biophysics and Molecular Biology. 2006;92(1):4-8.

23. Ceglia L. Vitamin D and its role in skeletal muscle. Curr Opin Clin Nutr Metab Care. 2009;12(6):628-33.

24. Stenholm S, Sallinen J, Koster A, Rantanen T, Sainio P, Heliövaara M, et al. Association between obesity history and hand grip strength in older adults-exploring the roles of inflammation and insulin resistance as mediating factors. J Gerontol A Biol Sci Med Sci. 2011;66(3):341-8.

25. Massa J, Stone KL, Wei EK, Harrison SL, Barrett-Connor E, Lane NE, et al. Vitamin D and actigraphic sleep outcomes in older community-dwelling men: the MrOS sleep study. Sleep. 2015;38(2):251-7.

26. Van Proeyen K, Szlufcik K, Nielens H, Pelgrim K, Deldicque L, Hesselink M, et al. Training in the fasted state improves glucose tolerance during fat-rich diet. J Physiol. 2010;588(Pt 21):4289-302.

27. Moran M, Van Cauwenberg J, Hercky-Linnewiel R, Cerin E, Deforche B, Plaut P. Understanding the relationships between the physical environment and physical activity in older adults: a systematic review of qualitative studies. Int J Behav Nutr Phys Act. 2014;11:79.

28. Beard JR, Blaney S, Cerda M, Frye V, Lovasi GS, Ompad D, et al. Neighborhood characteristics and disability in older adults. The journals of gerontology Series B, Psychological sciences and social sciences. 2009;64(2):252-7.

\section{Tables}

Table 1. Participants' characteristics $(n=118)$ 


\begin{tabular}{|lll|}
\hline Categorical variables & $\mathrm{N}$ & $\%$ \\
\hline Sex: female & 83 & 70.3 \\
\hline Marital status: married & 78 & 66.1 \\
\hline Employment: no full-time job & 114 & 96.6 \\
\hline Living status: living alone & 11 & 9.3 \\
\hline Educational level: tertiary & 26 & 22.0 \\
\hline Self-rated health: good & 36 & 30.5 \\
\hline Depression: yes & 16 & 13.6 \\
\hline Hypertension: yes & 44 & 37.3 \\
\hline Hyperlipidemia:yes & 35 & 29.7 \\
\hline Diabetes: yes & 22 & 18.6 \\
\hline Continuous variables & mean & SD \\
\hline Age (year) & 70.0 & 5.0 \\
\hline Body mass index $\left(\mathrm{kg} / \mathrm{m}^{2}\right.$ ) & 24.2 & 3.5 \\
\hline Monitor wear time (hours/day) & 15.4 & 15.5 \\
\hline Moderate-to-vigorous physical activity & & \\
\hline Overall (hours/day) & 0.4 & 0.4 \\
\hline During the morning ${ }^{1}$ (\%) & 47.7 & 16.1 \\
\hline During the afternoon ${ }^{2}$ (\%) & 29.9 & 10.0 \\
\hline During the evening ${ }^{3}$ (\%) & 21.6 & 11.1 \\
\hline
\end{tabular}

${ }^{1}$ During the morning: 06:01-12:00; ${ }^{2}$ During the afternoon: $12: 01-18: 00 ;{ }^{3}$ During the evening: 18:01-24:00.

SD: standard deviation; Cl: confidence interval

Note: the sum of percentages of MVPA during the morning, afternoon, and evening were not $100.0 \%$ because each percentage of time interval was an average of 118 participants.

Table 2. Associationsof overall and timing-specific moderate-to-vigorous physical activity with measures of physical function 


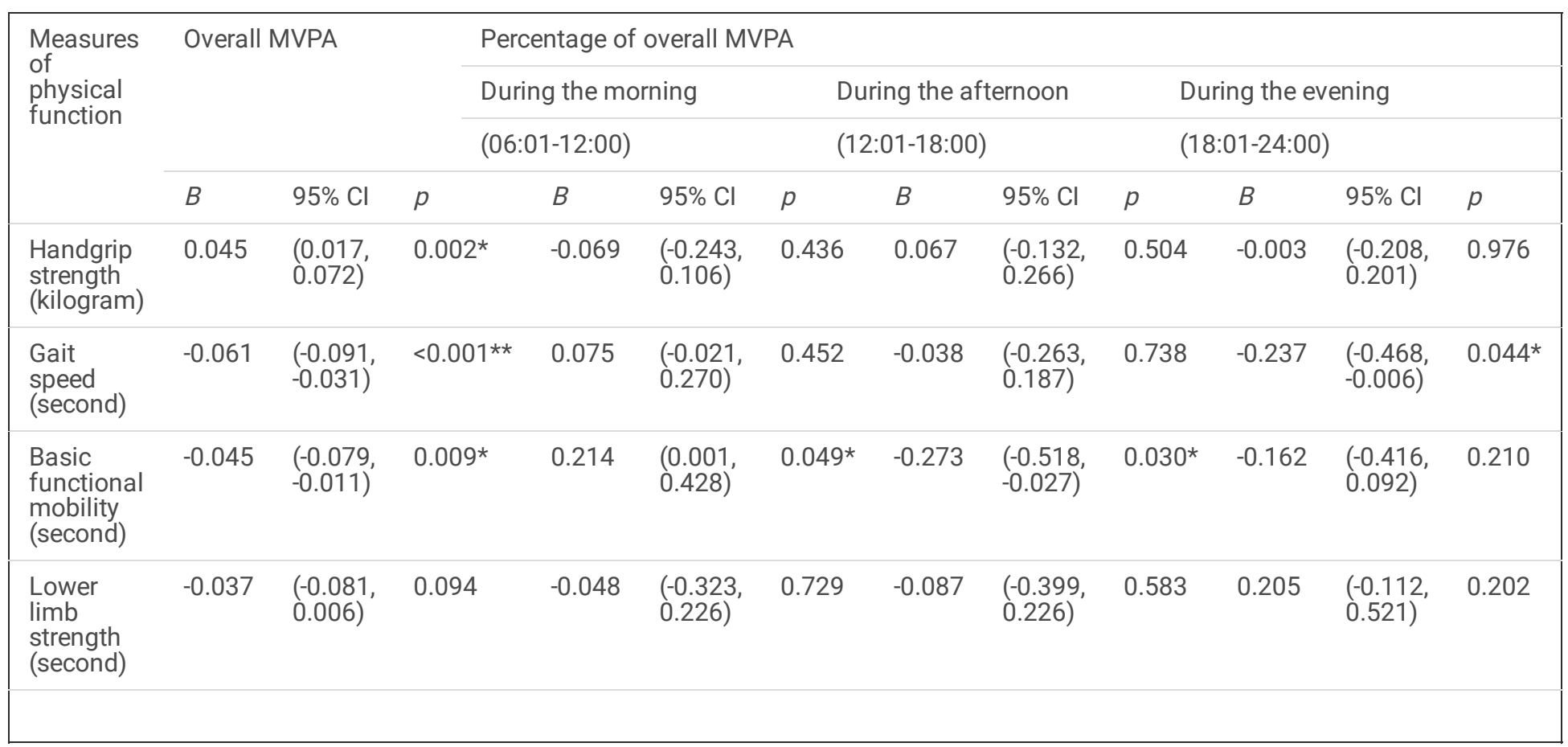

B: unstandardized linear regression coefficient;MVPA: moderate-to-vigorous physical activity;Cl: confidence interval

${ }^{\star} p<0.05 ;{ }^{* *} p<0.001$

\section{Appendix}

\section{Appendix Table 1. The univariate linear regression models with measures of physical function}




\begin{tabular}{|c|c|c|c|c|}
\hline \multirow[t]{2}{*}{ Categorical variables } & Handgrip strength & Gait speed & $\begin{array}{l}\text { Basic functional } \\
\text { mobility }\end{array}$ & $\begin{array}{l}\text { Lower limb } \\
\text { strength }\end{array}$ \\
\hline & $B(95 \% \mathrm{Cl})$ & $B(95 \% \mathrm{Cl})$ & $B(95 \% \mathrm{Cl})$ & $B(95 \% \mathrm{Cl})$ \\
\hline Sex: female & $\begin{array}{l}-0.186(-0.218 \\
-0.155)^{\star}\end{array}$ & $0.043(0.004,0.082)^{*}$ & $0.013(-0.031,0.057)$ & $-0.014(-0.064,0.037)$ \\
\hline Marital status: married & $\begin{array}{l}-0.059(-0.103 \\
-0.016)^{\star}\end{array}$ & $0.050(0.013,0.088)^{\star}$ & $0.039(-0.003,0.080)$ & $0.013(-0.036,0.062)$ \\
\hline Employment: no full-time job & $0.101(-0.015,0.217)$ & $-0.020(-0.120,0.080)$ & $-0.058(-0.168,0.053)$ & $-0.049(-0.177,0.079)$ \\
\hline Living status: living alone & $0.041(-0.032,0.113)$ & $-0.022(-0.084,0.041)$ & $-0.031(-0.100,0.038)$ & $-0.082(-0.161,-0.004)^{*}$ \\
\hline Educational level: tertiary & $0.025(-0.031,0.081)$ & $0.071(0.029,0.113)^{*}$ & $0.066(-0.019,0.122)^{\star}$ & $0.025(-0.031,0.081)$ \\
\hline Self-rated health: good & $\begin{array}{l}-0.053(-0.099 \\
-0.008)^{\star}\end{array}$ & $0.056(0.019,0.094)^{*}$ & $0.071(0.030,0.113)^{\star}$ & $0.081(0.033,0.130)^{\star}$ \\
\hline Depression: yes & $0.077(0.017,0.138)^{\star}$ & $\begin{array}{l}-0.064(-0.116 \\
-0.013)^{\star}\end{array}$ & $-0.076(-0.133,-0.019)^{*}$ & $-0.061(-0.128,0.006)$ \\
\hline Hypertension: yes & $-0.005(-0.049,0.039)$ & $\begin{array}{l}-0.038(-0.075 \\
-0.001)^{\star}\end{array}$ & $-0.040(-0.081,0.001)$ & $-0.031(-0.079,0.017)$ \\
\hline Hyperlipidemia:yes & $0.014(-0.033,0.060)$ & $\begin{array}{l}-0.045(-0.084 \\
-0.006)^{\star}\end{array}$ & $-0.053(-0.096,-0.010)^{*}$ & $-0.037(-0.087,0.014)$ \\
\hline Diabetes: yes & $0.024(-0.031,0.078)$ & $-0.030(-0.076,0.017)$ & $-0.051(-0.102,-0.001)^{\star}$ & $-0.019(-0.079,0.040)$ \\
\hline Continuous variables & $B(95 \% \mathrm{Cl})$ & $B(95 \% \mathrm{Cl})$ & $B(95 \% \mathrm{Cl})$ & $B(95 \% \mathrm{Cl})$ \\
\hline Age (year) & $\begin{array}{l}-1.050(-1.726 \\
-0.373)^{\star}\end{array}$ & $1.220(0.665,1.775)^{\star}$ & $1.271(0.649,1.893)^{\star}$ & $0.960(0.212,0.463)^{\star}$ \\
\hline Body mass index $\left(\mathrm{kg} / \mathrm{m}^{2}\right)$ & $0.130(-0.216,0.476)$ & $0.502(0.222,0.782)^{*}$ & $0.480(0.165,0.796)^{\star}$ & $0.219(-0.158,0.596)$ \\
\hline $\begin{array}{l}\text { Monitor wear time } \\
\text { (hours/day) }\end{array}$ & $\begin{array}{l}-0.019(-0.035 \\
-0.004)^{\star}\end{array}$ & $-0.006(-0.019,0.007)$ & $-0.001(-0.016,0.014)$ & $-0.006(-0.023 .0 .011)$ \\
\hline
\end{tabular}

$B$ : unstandardized linear regression coefficient; $\mathrm{Cl}$ : confidence interval

${ }^{\star} p<0.05$ 